\title{
“A burguesia fede": uma análise da formação discursiva na canção de Cazuza
}

\author{
Hudson Marques da Silva* \\ Josimere Maria da Silva** \\ Davi da Silva Gouveia ${ }^{* * *}$
}

Resumo: Este trabalho propõe uma análise da canção Burguesia (1989), de Cazuza, fundamentada na análise de discurso de linha francesa. Promover uma leitura das formações ideológicas e interdiscursos materializados na formação discursiva dessa canção constitui seu principal objetivo. A abordagem teórico-metodológica parte de alguns conceitos basilares da ADF: formação ideológica, formação discursiva, interdiscurso, efeito metafórico (PÊCHEUX, 1995, 1997), designação, referência (GUIMARÃES, 2001, 2002, 2003) e sequências discursivas (COURTINE, 2014). Verificou-se que o corpus apresenta uma FD sintomática de uma sociedade politicamente polarizada e que, na promoção de efeitos metafóricos, analogias e referenciação na designação de burguesia, estabelece interdiscursos identificados no marxismo.

Palavras-chave: Análise de Discurso. Canção Burguesia. Formações Ideológicas. Interdiscurso.

Abstract: This paper presents an analysis on the song Burguesia (Bourgeoisie) (1989), by Cazuza, based on French discourse analysis. The purpose is to promote an interpretation of the ideological formations and interdiscourses materialized in the discursive formation of this song. The theoretical-methodological approach starts from basic concepts of FDA: ideological formation, discursive formation, interdiscourse, metaphor effect (PÊCHEUX, 1995, 1997), designation, reference (GUIMARÃES, 2001, 2002, 2003), and discursive sequences (COURTINE, 2014). It was verified that this corpus presents a typical DF of a politically polarized society. Moreover, by using metaphor effects, analogies and referencing to designate bourgeoisie, it establishes interdiscourses with Marxism.

Keywords: Discourse Analysis. Song Burguesia. Ideological Formations. Interdiscourse.

Resumen: Este trabajo propone un análisis de la canción Burguesia (1989), de Cazuza, basado en el análisis del discurso francés. Promover una lectura de formaciones ideológicas y interdiscursos materializados en la formación discursiva de esta canción es su principal objetivo. El abordaje teórico-metodológico considera conceptos de la ADF: formación ideológica,

\footnotetext{
${ }^{*}$ Doutor em Literatura e Interculturalidade pela Universidade Estadual da Paraíba (UEPB). Docente do Instituto Federal de Educação, Ciência e Tecnologia de Pernambuco (IFPE). http://orcid.org/oooo-oooz8468-1469 / E-mail: marqueshudson@hotmail.com

** Doutora em Literatura e Interculturalidade pela Universidade Estadual da Paraíba (UEPB). Docente do Instituto Federal de Educação, Ciência e Tecnologia de Alagoas (IFAL). http://orcid.org/000o-00o1-69214021 / E-mail: josimariaifal@gmail.com

*** Mestre em Literatura e Interculturalidade pela Universidade Estadual da Paraíba (UEPB). http://orcid.org/oooo-0002-6480-108o / E-mail: david_rvb@hotmail.com
} 
formación discursiva, interdiscurso, efecto metafórico (PÊCHEUX, 1995, 1997), designación, referencia (GUIMARÃES, 2001, 2002, 2003) y secuencias discursivas (COURTINE, 2014). Se constató que el corpus presenta una FD sintomática de una sociedad políticamente polarizada y que, con efectos metafóricos, analogías y referencias para la designación de burguesía, establece interdiscursos en el marxismo.

Palabras clave: Análisis del Discurso. Canción Burguesia. Formaciones Ideológicas. Interdiscurso.

\section{Introdução}

Desde o seu advento, nos anos 1960, a Análise de Discurso (AD) tem contribuído consideravelmente não apenas para os estudos em ciências da linguagem, que têm nas manifestações linguageiras seu principal objeto de estudo, mas também para as ciências humanas em geral, na medida em que a $\mathrm{AD}$ é, por natureza, uma abordagem interdisciplinar ou, nos termos de Charaudeau (2005, n.p., grifo nosso), “[...] uma problemática global (que será necessariamente transdisciplinar).”.

Dentro de seus diversos objetivos, de sua ampla, distinta e movediça definição teórica, que inclui nomes da linha francesa como Foucault, Pêcheux, Maingueneau (AD), Charaudeau (semiolinguística), ou, na ótica da Análise Crítica de Discurso (ACD), Fairclough (discurso enquanto prática social) e Van Dijk (cognitivismo), a AD tem se voltado, sobretudo, para as formações ideológicas materializadas em discursos que têm interferido na sociedade, especialmente para a preservação do privilégio daqueles que se mantêm no poder e, por outro lado, para a discriminação ou justificação dos que têm permanecido em uma posição social subjugada ou subalternizada.

Ao utilizar como ferramenta de análise alguns conceitos teóricos da $\mathrm{AD}$ francesa, tais como formação ideológica (FI), formação discursiva (FD), interdiscurso, efeito metafórico (PÊCHEUX, 1995, 1997), designação, referência (GUIMARÃES, 2001, 2002, 2003) e sequências discursivas (SDs) (COURTINE, 2014), o principal propósito deste trabalho consiste em promover uma leitura das formações ideológicas e interdiscursos que materializam a FD da canção Burguesia (1989), de Cazuza.

A motivação para a escolha deste corpus nasce de algumas premissas: a) a canção Burguesia foi lançada em 1989, um ano-chave nas mudanças sociopolíticas globais com 
o fim da Guerra Fria. No caso brasileiro, é o ano de retomada das eleições diretas e, portanto, a consolidação do fim do Regime Militar. Torna-se possível, então, encontrar nessa canção um discurso indicial (ou porta-voz), que representa os adversários daquele governo que fora apoiado por uma parcela da classe social denominada burguesia; b) a canção Burguesia é a faixa título de um álbum que vendeu milhares de cópias país afora, reproduzida nas rádios e TV, portanto, um discurso que foi consideravelmente veiculado entre a população brasileira, o que possibilitou que o verso "A burguesia fede" se tornasse uma espécie de "dito popular" até hoje; c) a canção Burguesia apresenta uma FD sintomática de uma sociedade politicamente polarizada em função de seu contexto histórico já mencionado, o que tem sobremaneira ressurgido no Brasil desde 2014 e, principalmente, a partir de 2016, quando um governo identificado com a esquerda foi destituído do poder com o apoio de grupos opositores, nomeadamente de direita. Esses eventos políticos mais recentes catalisaram um conflito de classes (e de discursos) que evoca o que se identifica na FD da canção em pauta, o que torna essa abordagem interessante para o contexto atual, ainda que não seja o propósito deste trabalho realizar uma comparação entre os dois momentos históricos; d) no geral, a maioria dos trabalhos de $\mathrm{AD}$ têm se debruçado sobre discursos realizados por políticos, manchetes de jornais, matérias de revistas ou publicidade, embora o gênero canção possa representar uma importante maquinaria discursiva que, se por um lado pode alcançar expressivamente seu expectador-ouvinte, por outro, consegue atravessar décadas sendo reproduzida, reinterpretada, influenciando, então, outras FDs.

Destarte, trata-se de um trabalho interpretativo fundamentado em conceitos basilares da AD de linha francesa sobre um corpus representativo da polarização política brasileira, em especial de como a classe social economicamente privilegiada, designada "burguesia”, é referenciada no discurso opositor. Embora não se ouse aqui uma análise neutra, que certamente seria impossível, pois todo gesto interpretativo penetra a seara da subjetividade, não se pretende promover um julgamento moral acerca das FIs e interdiscursos identificados na FD do corpus estudado, intenta-se tão somente interpretá-los, encontrar possíveis associações interdiscursivas e verificar como esse encadeamento de discursos é materializado na canção. 


\section{Aspectos teórico-metodológicos}

Em conformidade com os propósitos da análise do corpus neste trabalho, esta seção mobiliza, muito brevemente, apenas os conceitos que lhe são empregados, sem intenções de aprofundar ou discorrer exaustivamente acerca da ADF, visto que essa tarefa já foi (e ainda tem sido) empreendida por diversas outras pesquisas publicadas em forma de livros, teses, dissertações, artigos, etc., pois não constitui o principal objetivo aqui, cujo foco encontra-se na análise da canção Burguesia.

Antes de tudo, é importante frisar que não existe unidade teórica ou conceitual na $\mathrm{ADF}$, que tem se revelado variável tanto entre os diferentes autores, (por exemplo, a noção de FD pecheutiana diverge de seu conceito inaugurado na Arqueologia de Foucault (2008) quanto na própria trajetória de Michel Pêcheux, que, em pouco mais de duas décadas de publicações, realizou algumas retificações em sua compreensão sobre a AD. Em vista disso, é inteirada dessa oscilação que esta abordagem teórica expõe os conceitos-chave, desdobrados aqui a partir de uma dada concepção.

Na ADF pecheutiana, ideologia, discurso, interdiscurso e sujeito são fenômenos interconectados. Isto é, a ideologia interpela o sujeito, que materializa o discurso, que, por sua vez, é formado por interdiscursos e pelo encontro de diversas posições-sujeito. A visão pecheutiana sobre ideologia tem em pensadores marxistas, especialmente em Althusser, seu ponto de partida. Trata-se, portanto, de uma percepção em que a ideologia está sempre relacionada à luta de classes. Nesse âmbito, as variedades ideológicas, denominadas formações ideológicas (FIs) por Pêcheux, fundamentam o discurso na medida em que "[...] todo processo discursivo se inscreve numa relação ideológica de classes." (PÊCHEUX, 1995, p. 92). Portanto, as FIs encontram-se na práxis social e em seus diversos canais de representação no percurso histórico, não sendo nem "individuais" nem "universais", uma vez que se estabelecem em uma relação intersticial de confronto entre as classes sociais (perspectiva do materialismo histórico marxista).

Nessa trilha teórica, ainda que as FIs estejam arraigadas no universo extralinguístico (nos aparelhos de Estado (althusserianos), no confronto entre classes 
sociais (marxista), no próprio arranjo social, etc.), o que mais interessa nesta análise é como as FIs materializam as formações discursivas (FDs), e como essas FDs estão consubstanciadas em outras FDs (interdiscurso), compreendendo FD como zonas de "regularidades discursivas", ainda que tais regularidades não sejam homogêneas, conforme retificou Pêcheux em sua última fase. Os sentidos engendrados por determinada FD dependem, pois, de sua relação com outras FDs, que ora convergem, ora se dispersam. Em face desse fenômeno, cumpre pressupor que os efeitos de sentido produzidos em toda FD dependem do interdiscurso.

Tomando como ponto de partida essas concepções iniciais, podem-se indicar alguns fenômenos discursivos e linguísticos que serão referenciados no decorrer da análise de corpus aqui proposta: efeito metafórico, designação e referência.

O efeito metafórico é definido por Pêcheux em Análise Automática do Discurso (1969), como uma espécie de "deslizamento de sentido" que ocorre em determinadas palavras. Trata-se, portanto, de um "[...] fenômeno semântico produzido por uma substituição contextual [...]" (PÊCHEUX, 1997, p. 96). É justamente em função disso que as palavras não mantêm em si um significado ou um único sentido, ao passo que transcendem a todo o momento sua semântica convencional. Nos termos de Pêcheux (1995, p. 160), “[...] as palavras, expressões, proposições, etc., mudam de sentido segundo as posições sustentadas por aqueles que as empregam”. Dessa forma, as práticas discursivas geram novas e infinitas possibilidades de significação em estruturas sintático-morfológico-lexicais, que são apreendidas conforme as intenções discursivas de seus enunciadores, e o conhecimento prévio e contextualização de seus receptores.

No que diz respeito à noção de designação e referência, recorre-se aqui a Guimarães (2014, 2002, 2003), em que, a designação identifica por um nome aquilo sobre o que fala, sendo então "[...] a significação de um nome enquanto sua relação com outros nomes e com o mundo recortado historicamente pelo nome." (GUIMARÃES, 2003, p. 54). Já a referência reporta ao processo de caracterização da designação: com quais outros referentes são comparados (analogias), quais componentes lhe são atribuídos. Assim, se a designação consiste no que "[...] se poderia chamar de significação de um nome [...]", a "referência será vista como a particularização de algo na e pela enunciação." (GUIMARÃES, 2002, p. 09). 
Por fim, no tratamento de determinado corpus discursivo, as posições ideológicas materializadas em discurso, seja oral ou escrito, podem ser denominadas sequências discursivas (SDs), tomando emprestado aqui o conceito desenvolvido por Courtine (2014), segundo o qual as SDs representam a composição estrutural de todo corpus discursivo. As SDs não se referem a frases, mas a discursivizações ideológicas que podem ser homogêneas/heterogêneas ou sincrônicas/diacrônicas. Em síntese, no corpus discursivo, determinada designação pode ser referenciada por efeitos metafóricos (ou outras estratégias), enquanto recurso linguístico-discursivo de materialização de FIs. E tal materialização, ou seja, tal FD, não é única e original daquele sujeito discursivo, mas formada pelo cruzamento de outras posições-sujeito, o que caracteriza a FD como substância de algo pré-existente.

\section{Identificação e contextualização do corpus}

O corpus selecionado para esta análise é a canção Burguesia, cuja composição e interpretação foram lançadas por Cazuza (Agenor de Miranda Araújo Neto) em 1989, no álbum de mesmo título, quando o artista já se encontrava fragilizado por complicações da AIDS, tendo gravado algumas faixas, deitado na cama e com voz frágil (ARAÚJO, 2011).

O ano de 1989 foi emblemático não somente em termos nacionais como também globais, uma vez que, se no Brasil seria o ano das primeiras eleições diretas após décadas de Regime Militar, em perspectiva mundial testemunhava-se o desfecho da Guerra Fria iconizado pela queda do muro de Berlim. Isto significa que era um período de mudanças na política. Essas mudanças eram percebidas pelo povo e registradas no imaginário popular. No caso brasileiro, tais mudanças comportavam uma redemocratização e, concomitantemente, a liberdade de expressão que, outrora, fora policiada e censurada.

Enquanto crepúsculo dos governos autoritários brasileiros, a década de 1980 foi um período fértil para artistas veicularem críticas sociais em suas obras, incluindo aqui o rock nacional, cujas canções-manifesto eram reproduzidas em programas de rádio ou 
executadas em programas televisivos, além dos altos números de vendas de álbuns que as popularizavam entre uma parcela representativa da população; o álbum Burguesia, por exemplo, teve mais de 250 mil cópias vendidas. Com efeito, em geral, a maioria dos brasileiros sabia quem era Cazuza, ou mesmo, conhecia o famoso verso "A burguesia fede”, que se perpetuou até hoje.

Notadamente, a canção Burguesia simbolizava uma reação aos economicamente privilegiados dentro de um país tão desigual, em que a maioria da população vivia (e ainda vive) na pobreza. Mas não só isso, a canção era uma contestação contra uma classe que, na visão do artista (e de muitos), teria apoiado e/ou financiado o governo dos militares, como será elucidado na seção subsequente.

Portanto, a canção Burguesia parece sintetizar algumas FIs materializadas pelas FDs adversárias ao Regime Militar, às classes economicamente prestigiadas e àquilo que se convencionou chamar de "direita”, como se pode verificar na seção seguinte.

\section{Burguesia: análise do corpus}

Considerando os propósitos deste trabalho, enquanto gesto interpretativo fundamentado nos pressupostos teóricos da $\mathrm{ADF}$, os versos da canção Burguesia serão denominados sequências discursivas (SDs), enumeradas de acordo com sua contiguidade semântica para fins metodológicos, bem como o eu lírico será referenciado como sujeito discursivo. Essas alterações têm como pretensão aproximar da AD o olhar analítico em vez da teoria literária.

Burguesia - Cazuza

SD1 A burguesia fede

SD2 A burguesia quer ficar rica

SD3 Enquanto houver burguesia Não vai haver poesia

SD4 A burguesia não tem charme nem é discreta

$\mathrm{SD}_{5}$ Com suas perucas de cabelo de boneca 
SD6 A burguesia quer ser sócia do Country

Quer ir a Nova York fazer compras, yeah

SD7 Pobre de mim que vim do seio da burguesia

SD8 Sou rico mas não sou mesquinho

SD9 Eu também cheiro mal

Eu também cheiro mal

SDio A burguesia tá acabando com a Barra

Afundam barcos cheios de crianças

E dormem tranquilos

E dormem tranquilos

SD11 Os guardanapos estão sempre limpos

As empregadas, uniformizadas

SD12 São caboclos querendo ser ingleses

São caboclos querendo ser ingleses

SD13 A burguesia não repara na dor

Da vendedora de chicletes

SD14 A burguesia só olha pra si

A burguesia só olha pra si

SD15 A burguesia é a direita, é a guerra

SD16 As pessoas vão ver que estão sendo roubadas

SD17 Vai haver uma revolução

SD18 Ao contrário da de 64

SD19 O Brasil é medroso

SD2o Vamos pegar o dinheiro roubado da burguesia

SD21 Vamos pra rua

Vamos pra rua

Vamos pra rua

Vamos pra rua

Pra rua

Pra rua

SD22 Vamos acabar com a burguesia

SD23 Vamos dinamitar a burguesia

SD24 Vamos pôr a burguesia na cadeia

SD25 Numa fazenda de trabalhos forçados

SD26 Eu sou burguês, mas eu sou artista

Estou do lado do povo, do povo

SD27 Porcos num chiqueiro

São mais dignos que um burguês 
SD28 Mas também existe o bom burguês Que vive do seu trabalho honestamente

SD29 Mas este quer construir um país

E não abandoná-lo com uma pasta de dólares

SD30 O bom burguês é como o operário

SD31 É o médico que cobra menos pra quem não tem

$\mathrm{SD}_{32}$ E se interessa por seu povo

SD33 Em seres humanos vivendo como bichos

Tentando te enforcar na janela do carro

No sinal, no sinal

No sinal, no sinal, no sinal

SD1 A burguesia fede

SD9 Eu também cheiro mal

SD3 Enquanto houver burguesia

Não vai haver poesia

O ponto de partida desta análise consiste na identificação, na SD1 e SD9, de uma sinonímia não-contextual, já que seus sintagmas verbais são substituíveis em qualquer contexto. Todavia, tanto o verbo "feder" quanto o modalizador "cheirar mal" configuram um efeito metafórico em função de sua substituição semântica, em que o mau cheiro representa o caráter negativo atribuído à classe social designada burguesia. Da metáfora do mau odor, ainda que um tanto abstrata a priori, é possível presumir toda a caracterização detratória que será desdobrada ao longo da canção. Desta feita, a elucidação dessa metáfora introdutória vai se revelando cataforicamente nas SDs subsequentes, ainda que o significado original do verbete já possa imprimir pistas de algo desagradável, negativo e pejorativo. A SDı é empregada como um pressuposto de que a burguesia mantém, naturalmente, tais atributos pejorativos e, portanto, se o sujeito discursivo assume sua própria origem como sendo da classe social criticada, ele também, sobremaneira, carregaria consigo os traços a ela associados.

Com a SD2, levando em conta sua intercalação com a SD1 e SD3, ambas depreciativas, o sujeito discursivo promove um juízo de valor moral negativo no desejo ou propósito de enriquecimento. A relação entre essas SDs provoca um efeito de sentido em que, querer "ficar rica” seria, pois, igual a "feder" e, por isso, "não vai haver poesia”, 
entendendo-se aqui o termo poesia como metáfora de uma sociedade coesa e harmônica, já que o gênero poesia apresenta certa métrica e, muitas vezes, rima entre as palavras.

Em outros termos, o desejo de "ficar rica" da burguesia, que nesta SD revela uma ambivalência, pois a burguesia já é rica (talvez almejando cada vez mais riqueza), seria incompatível com a harmonia social. Existe nesse pensamento uma possível associação com o marxismo (que se revelará mais adiante), na medida em que "ficar rica" reporta à acumulação de bens ou, em termos marxistas, detenção do capital. Na teoria marxista, a detenção do capital por parte de uma minoria pressupõe a exploração do trabalho da maioria. Com base nisso, no desejo de "ficar rica" da burguesia, que estabelece o interdiscurso com a detenção do capital de Marx, residiria o embrião da desarmonia e das mazelas sociais, e, portanto, do "fedor" burguês.

A SD3 anuncia a solução para esse problema: o fim da burguesia. Esse excerto, se considerado o interdiscurso com a teoria marxista, representaria não a eliminação (morte) dos burgueses, mas o fim da classe social burguesa, isto é, o fim da estrutura de detenção do capital pela burguesia, como explorado por Marx e Engels (1999) no Manifesto Comunista. Destarte, a FD da canção surge em um contexto cujas formações ideológicas podem ser identificadas com algumas proposições desses pensadores.

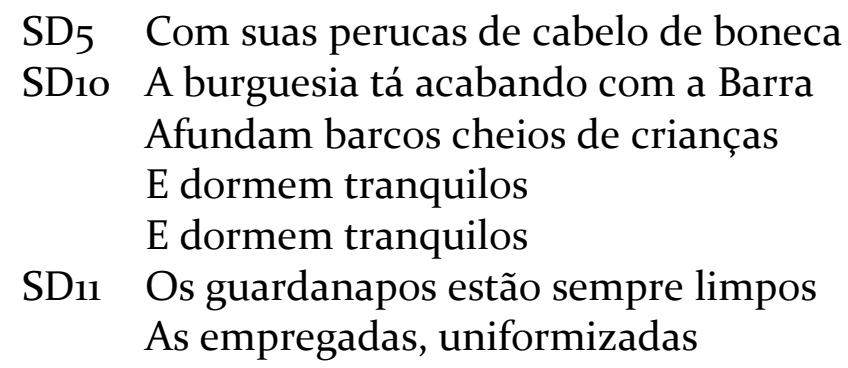

No processo de referência a respeito da designação burguesia, a $\mathrm{SD}_{5}$ sugere uma versão atualizada do fetichismo da mercadoria marxista, a partir da qual, o consumidor (cidadão com potencial econômico) é dominado pela necessidade de adquirir bens e produtos como sinônimos de felicidade e sucesso, o que seria (nas visões de origem marxista mais recentes) uma estratégia mercadológica para se vender mais. "Perucas" e "cabelos de boneca" simbolizariam, nessa ótica, o universo da "boa" aparência comprada pelo burguês e extremamente associada ao poder de consumo, que incluiria desde 
procedimentos estéticos na aparência física (cirurgias plásticas, implantes, maquiagens, etc.), até produtos-ícone de alto padrão socioeconômico (casarões em bairros de luxo, modelos de automóveis caros, etc.).

Toda essa elaboração imagético-discursiva desenhada pela SD5 e SDı engendra uma feição artificial para a burguesia, que conota também uma natureza falsa, superficial, fútil. Isso alude, então, à artificialidade e superficialidade do burguês, ao seu caráter egoísta e excludente. Em outras palavras, pode-se inferir uma relação de causa e efeito em que, a classe burguesa deteria o capital à custa da exploração do trabalho alheio (efeito) porque é superficial (causa), não se comove com a injustiça social, financia práticas perversas e "dormem tranquilos", conforme a SD10, que, como recurso enfático, se repete duas vezes na canção.

\section{SD6 A burguesia quer ser sócia do Country Quer ir a Nova York fazer compras, yeah \\ SD12 São caboclos querendo ser ingleses São caboclos querendo ser ingleses}

Com a SD12, o sujeito discursivo, no processo de referência ao burguês, traz à pauta um tópico recorrente no debate nacional desde a independência do país: a identidade. O emprego do sintagma adjetival "caboclo" atribui ao burguês, enquanto brasileiro, uma origem miscigenada, especialmente com a figura do indígena, como já fora abordada em momentos históricos mais distantes, pela literatura brasileira romântica do século XIX, ou pelos modernistas do início do século XX, entre outros.

A despeito da recorrência de abordagens sobre a miscigenação, que envolve europeus-africanos-indígenas como parte da identidade nacional, denuncia-se na canção a existência de uma autonegação por parte das classes prestigiadas brasileiras, quanto a identidade nacional, que, além de miscigenada, é também sincrética, multifacetada nas variedades linguísticas e nas influências culturais.

Em negação de sua própria realidade identitária, o burguês sempre teve como ideal o modelo europeu, branco, judaico-cristão, identificado nos colonizadores. Por isso, "São caboclos querendo ser ingleses". Essa pauta é prenunciada com a SD6, em que o hábito de (ou o desejo de apenas) fazer compras em outros países, especialmente 
países hegemônicos como os EUA, revelaria a desvalorização que a burguesia preserva pelo seu próprio país, visando o outro, o externo, como melhor, como superior e, por isso, o lugar ideal para compras seria "Nova York" em vez de uma cidade brasileira. Nova York funciona nessa SD como uma metonímia das cidades estrangeiras tidas como "sofisticadas", como caras, o que elevaria o status da burguesia.

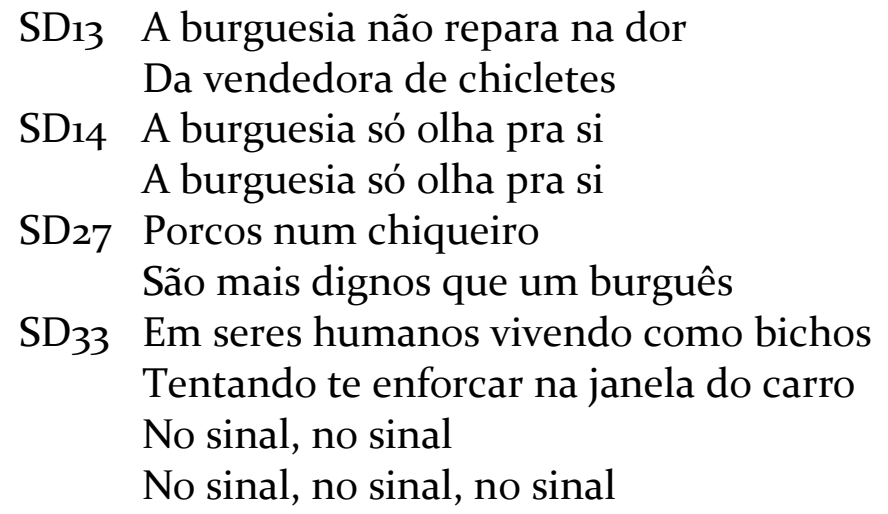

No decorrer da canção, pode-se notar uma intensificação gradativa da referência depreciativa sobre a figura do burguês. De modo mais direto, o sujeito discursivo acusa essa classe de insensível e sem empatia, como se verifica na SD13 e SD14. A introdução da "vendedora de chicletes" nesse excerto reporta a uma cena comum nas cidades: pessoas que ficam nos semáforos, ora tentando vender produtos e exibições artísticas, ora oferecendo limpeza dos para-brisas ou, por diversas vezes, apenas pedindo dinheiro aos ocupantes dos automóveis.

A cena referenciada é um dos retratos da pobreza, vista na ótica marxista como resultado da desigualdade social. Essa justaposição entre os automóveis fechados, ocupados por uma classe economicamente prestigiada, em contraste com os sobreviventes das ruas, simbolizaria uma espécie de fronteira latente entre dominantes e dominados, recorrendo aqui a termos marxistas. Essa cena é retomada mais adiante com a SD33, em que os sobreviventes do sinal são comparados a "bichos", ou seja, não vivem de modo digno como seres humanos, mas como animais abandonados. A comparação entre humanos e animais também é realizada com a burguesia na SD27, em que "porcos num chiqueiro" teriam mais dignidade do que um burguês. O chiqueiro é um ambiente fétido, ratificando assim a metáfora do mau odor que abre a canção. Em 
vista disso, diferentemente dos "humanos-bichos" que viveriam nessa condição pela exclusão social e não por responsabilidade própria, o burguês-porco, por seu turno, não teria dignidade, pois é responsável pela sua prática insensível, exploratória e violenta.

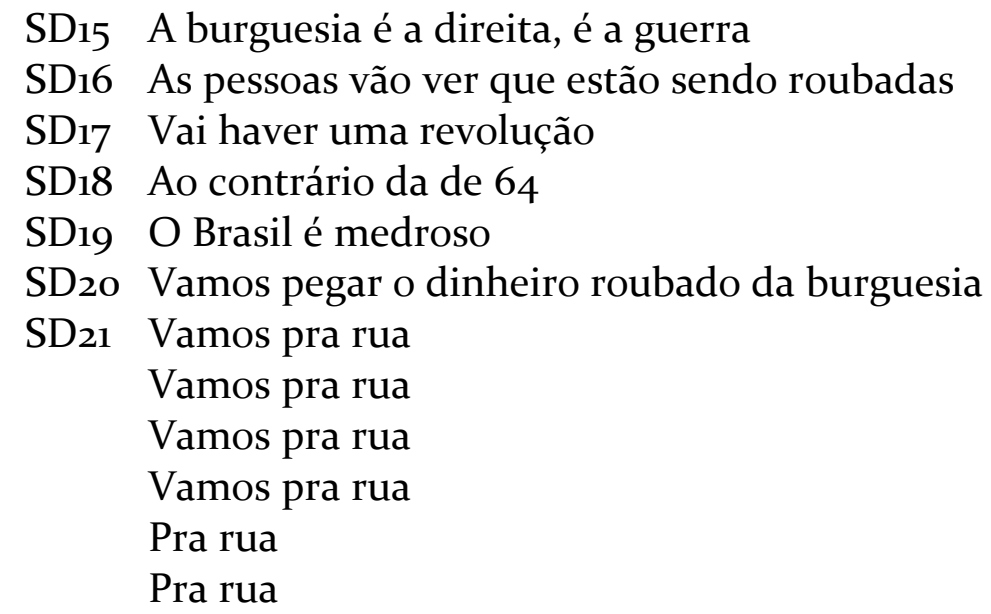

De forma mais explícita, o sujeito discursivo revela a defesa de uma posição política marxista ao afirmar, com a SD15, que "a burguesia é a direita”. Essa declaração implica uma designação para essa classe social, em que burguesia e a direita seriam correspondentes ou análogas. Acrescenta-se ainda "a guerra" como traço imanente da burguesia-direita. Dito de outro modo, essa classe social, acompanhada de sua posição política direitista, seria violenta porque nela residiria a raiz dos conflitos violentos. Verifica-se na SD15 certa polarização ao generalizar "direita” como posicionamento da burguesia, como se não pudesse haver um número expressivo de burgueses identificados com a esquerda ou de trabalhadores identificados com a direita.

Nessa perspectiva, se a burguesia é egoísta, superficial, exploradora, violenta e, ainda, desonesta, ao estar roubando a população, como consta na SD16 e SD20, em que a burguesia estaria espoliando os menos favorecidos tanto pela exploração do trabalho, considerando a mais-valia marxista, quanto pela instrumentalização do governo, que direcionaria os impostos pagos pela população para o benefício dessa classe privilegiada, logo, é preciso haver uma revolução, conforme SD17. A revolução referenciada seria de esquerda, já que a SD18 a classifica como “Ao contrário da de 64", em referência ao Golpe Militar de 1964, quando os militares assumiram o governo do país e o conduziram por mais de duas décadas, sendo, pois, considerado um Regime Militar de direita. Para o 
sujeito discursivo, esse fenômeno histórico só teria acontecido porque "O Brasil é medroso", como consta na SD19. Se isso é verdadeiro, a maioria da população brasileira teria sido submissa e covarde ao permitir a imposição daquele governo sem se rebelar, sem realizar uma revolução, como evoca a canção, com a SD21, que se repete seis vezes.

SD22 Vamos acabar com a burguesia

SD23 Vamos dinamitar a burguesia

SD24 Vamos pôr a burguesia na cadeia

SD25 Numa fazenda de trabalhos forçados

Perante tanta imposição, exploração e injustiça social, com a SD22, SD23, SD24 e SD25, nota-se a promoção de um discurso de ódio, embora esse conceito, como se verifica no Guia de Análise de Discurso de Ódio (Fundação Getúlio Vargas, 2020, p. 4), remeta sempre às classes ou grupos vulneráveis, "Discursos de ódio são manifestações que avaliam negativamente um grupo vulnerável ou um indivíduo enquanto membro de um grupo vulnerável”. Contudo, neste caso, o discurso de ódio é veiculado contra as classes prestigiadas, visto que o sujeito discursivo convoca seu espectador-ouvinte para "acabar com a burguesia”, porém não mais no sentido marxista mencionado anteriormente (pôr fim à classe social), e sim no sentido violento, como se pode verificar semanticamente no sintagma verbal "dinamitar" (SD23) e na alusão aos campos de concentração em "fazenda de trabalhos forçados" (SD25). Com esses excertos, a FD da canção resgata práticas violentas históricas que foram emblemáticas da Segunda Grande Guerra e repudiadas pela maioria da população mundial do pós-guerra. A formação ideológica que catalisa a FD da canção está ancorada em uma espécie de ressentimento e desejo de vingança como meio de fazer justiça social. O efeito de sentido produzido por esse discurso de ódio parece sugerir que somente sofrendo a burguesia poderia perceber o sofrimento dos excluídos.

SD26 Eu sou burguês, mas eu sou artista Estou do lado do povo, do povo

SD28 Mas também existe o bom burguês Que vive do seu trabalho honestamente

SD30 O bom burguês é como o operário

SD31 É o médico que cobra menos pra quem não tem 
A SD28, próxima à conclusão da canção, faz uma retificação que rompe com a generalização depreciativa contra o burguês exposta até então, ao ressaltar a existência do "bom burguês", que seria honesto e fiel ao seu país. O "bom burguês" é, curiosamente, comparado a um operário ( $\mathrm{SD}_{30}$ ), tido como bom exemplo. Desse modo, essa elaboração discursiva articula a ideia segundo a qual existiriam alguns burgueses bons, que seria uma minoria, enquanto os operários seriam todos bons. Nota-se nesse discurso uma formação ideológica de invasão do ódio entre as classes, em que a classe privilegiada seria sempre vilã e culpada por toda desarmonia social, enquanto o proletariado representaria as vítimas, os injustiçados, como sendo sempre "boas pessoas".

O "bom burguês" é referenciado como um "médico que cobra menos para quem não tem" (SD31). Com esse exemplo, nota-se uma alteração na designação do burguês marxista, que o compreende como o detentor dos meios de produção. $\mathrm{O}$ médico, na maioria dos casos, é um profissional liberal que, mesmo com um retorno financeiro que o posicione nas classes prestigiadas, não detém meios de produção nem seria o melhor exemplo de explorador da mão de obra alheia. Portanto, há um novo significado para "burguês" aplicado nessa FD, cuja relação encontra-se mais na condição econômica de vida do que na sua função na sociedade de mercado, como concebia Marx. Esse deslizamento de sentido revela como o significado das palavras não é fixo, pois se altera a todo o momento conforme as intenções discursivas que estão em jogo. O burguês dessa FD não se limita aos detentores dos meios de produção, mas comporta todos os privilegiados economicamente. Com essa exceção, da existência de alguns bons burgueses, exemplificado com o médico que ajuda os pobres, fica subentendido na SD26 que o próprio sujeito discursivo, representando o compositor-cantor Cazuza, como já dito, também se incluiria nessa classificação, por ser artista e por estar do lado do povo. Com o emprego da coordenada adversativa "Eu sou burguês, mas eu sou artista", seguida de uma coordenada conclusiva "Estou do lado do povo, do povo", essa SD pressupõe que ser artista anula a perversidade burguesa ou faz de alguém uma pessoa melhor, bem como, ser artista é sinônimo de estar do lado do povo.

Se o médico torna-se um bom burguês quando ajuda os pobres e o artista é, por natureza, um bom burguês (caso seja de origem burguesa), é possível compreender dessa 
FD que todo o juízo de valor moral nos significados de bom e mau - e seus respectivos sinônimos contextuais - no decorrer da canção, está fundamentado nos conceitos de coletivismo (valorização da coesão e desejo dos grupos) e individualismo (valorização dos objetivos individuais), a partir dos quais o bom burguês - e também o proletariado - estaria associado ao primeiro, e o mau burguês ao último.

Em última instância, considerando a semântica, os efeitos metafóricos, os efeitos de sentido produzidos pelas SDs na canção Burguesia, identifica-se um notório interdiscurso ou uma recuperação do discurso marxista em sua FD. Fica claro como essa FD não foi inaugurada pelo seu sujeito discursivo, visto que, como compreendia Pêcheux, o sujeito não é o criador original de seu discurso, mas ele é atravessado pelos discursos. A canção reproduz, com seu discurso, formações ideológicas bem anteriores a ela, existentes nas ciências humanas e traduzidas também às artes. $O$ contexto de lançamento dessa canção, conforme seção anterior, diz muito sobre as motivações para essa FD: um período de mudanças políticas e de muito ressentimento. No caso específico do Brasil, os artistas representam, em sua maioria, uma classe muito perseguida durante os anos de Regime Militar, muitos foram exilados e/ou censurados. Portanto, no geral, os artistas estavam na oposição ao governo militar direitista, o que fazia com que a classe artística fosse identificada com a esquerda (tomando aqui as designações direita e esquerda em um sentido bem genérico). Nesse aspecto, a canção Burguesia, talvez, represente todo um sentimento de reação reprimida durante décadas, uma espécie de manifesto que pôde então ser publicado e popularizado com o fim do governo adversário, como sugere Grangeia (2016). Seria, pois, o grito dos perdedores, daqueles que sofreram pressão e violência simbólica e física, mas um grito carregado de ódio e utopias, na crença de que um modelo coletivista, sem classes como queriam Marx e Engels, ou de um governo identificado com a esquerda, poderia ter possibilitado um Brasil diferente.

\section{Considerações finais}


Popularizada na voz de Cazuza, a canção Burguesia mantém no interior de sua FD uma concatenação de alguns discursos (interdiscursos), conforme pressupostos da ADF pecheutiana, sendo então essa interdiscursividade fundamentada por FIs do pensamento marxista, com enfoque em: luta de classes, coletivismo, detenção do capital, mais-valia, exploração da mão de obra, fetichismo da mercadoria, entre outros conceitos básicos dessa corrente filosófica e sociopolítica.

Essa FD tem em sua gênese o contexto bipolarizado do cenário político glocal, um fenômeno que tende a se repetir por vezes na história, como se verificou nos anos de Guerra Fria (no Brasil, nos anos de Regime Militar), quando a canção analisada foi gestada, mas também crescente a partir de 2014, para mencionar apenas dois exemplos. Nesse contexto, a canção Burguesia expõe posições-sujeito que transcendem um olhar individual de seu compositor-cantor, configurando então interdiscursos que representam determinada comunidade ou posicionamento sociopolítico: dos não simpatizantes dos governos ditos de direita e de todos os ingredientes associados: capitalismo, burguesia, mercadorias, etc.

É dessas posições-sujeito, portanto, que emana o ódio ao burguês, responsabilizado nesta FD por contribuir para a desigualdade social, manutenção da pobreza, hierarquização de classes, concentração de privilégios em alguns (na própria burguesia). Ademais, o ódio ao burguês nessa FD estaria fundamentado não somente em comportamentos sociais da classe alvo, mas também em sua própria natureza (des)humana, egoísta, insensível e fútil.

\section{Referências}

ARAÚJO, L. O tempo não para: viva Cazuza. Porto Alegre: Globo Livros, 2011.

BURGUESIA. [Compositor e intérprete]: Cazuza. Rio de Janeiro: Universal Music, 1989. 1 CD (1h 7min).

CHARAUDEAU, P. Uma análise semiolinguística do texto e do discurso. In: PAULIUKONIS, M. A. L.; GAVAZZI, S. (Orgs.). Da língua ao discurso: reflexões para o 
ensino. Rio de Janeiro: Lucerna, 2005, p. 11-27. Disponível em: < http://www.patrickcharaudeau.com/Uma-analise-semiolinguistica-do.html> Acesso em: o8 de dez de 2021. COURTINE, Jean-Jacques. Análise do discurso político: o discurso comunista endereçado aos cristãos. São Carlos: EduFScar, 2014.

FOUCAULT, M. A arqueologia do saber. Trad. Luiz Felipe Baeta Neves. 7. ed. RJ: Forense Universitária, 2008.

GUIMARÃES, Eduardo. Espaço de enunciação, cena enunciativa, designação. Fragmentum. Santa Maria (RS), n. 40, p. 49-68, jan/mar, 2014.

GUIMARÃES, Eduardo. Semântica do acontecimento: um estudo enunciativo da designação. Campinas: Pontes Editores, 2002.

GUIMARÃES, Eduardo. Designação e espaço de enunciação: um encontro político no cotidiano. Letras. n. 26, p. 53-62, 2003.

GRANGEIA, M. L. Brasil: Cazuza, Renato Russo e a transição democrática. Rio de Janeiro: Civilização Brasileira, 2016.

LUCCAS, V. N.; GOMES, F. V.; SALVADOR, J. P. F. Guia para análise de discurso de ódio. São Paulo, 2020. p.11. Disponível em: <https://bibliotec adigital.fgv.br/dspace/bitstream/handle/10438/28626/Guia\%2ode\%2oAn\%c3\%arlise\%2 ode\%2oDiscurso\%2ode\%20\%c3\%93dio.pdf?sequence=1\&isAllowed=y>. Acesso em: 24 out. 2021.

MARX, K.; ENGELS, F. Manifesto do Partido Comunista. 9. ed. Petrópolis, Rio de Janeiro: Vozes, 1999 .

PÊCHEUX, M. Análise automática do discurso (AAD-69). In: GADET, F.; Hak, T. (Orgs.). Por uma análise automática do discurso: uma introdução à obra de Michel Pêcheux. 3. ed. Campinas: UNICAMP, 1997.

PÊCHEUX, M. Semântica e discurso: uma crítica à afirmação do óbvio. 2. ed. Campinas: UNICAMP, 1995 .

Recebido em 20/04/2021. Aprovado em 30/08/2021. 